\title{
Editorial to the topical collection "Learning from spatial data: unveiling the geo-environment through quantitative approaches"
}

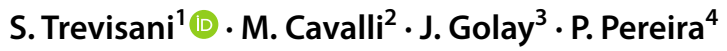

Received: 31 December 2018 / Accepted: 12 February 2019 / Published online: 18 February 2019

๑) Springer-Verlag GmbH Germany, part of Springer Nature 2019

The interactions between geoenvironmental and anthropic processes are increasing due to the ever-growing population and its related side effects (e.g., urban sprawl, natural resource and energy consumption, etc.). Natural hazards, land degradation, environmental pollution and climate change are some of the most evident results of the "interactions" between geosphere and anthroposphere. At a finer spatial scale, geo-environmental and geo-engineering issues in urban contexts or in the proximity of infrastructures represent a wide set of challenges that directly impact on the critical zone (e.g., Giardino and Houser 2015).

In this context, spatial and spatiotemporal data are crucial for the analysis, modelling and forecasting of the possible interactions between human activities and the geoenvironment. The technological developments achieved in field and laboratory instruments, including geophysical, proximal and remote-sensing devices, increase exponentially the amount and heterogeneity of geoenvironmental data that can be collected (e.g., Pereira et al. 2018). The ever-growing quantity of geoenvironmental data is distinguished by an extreme variability of information characteristics including its spatial sampling network geometry, its spatial support,

\section{S. Trevisani}

strevisani@iuav.it

M. Cavalli

marco.cavalli@irpi.cnr.it

P. Pereira

pereiraub@gmail.com

1 University IUAV of Venice, Dorsoduro 2206, Venice, Italy

2 National Research Council, Research Institute for Geo-Hydrological Protection, Corso Stati Uniti 4, Padua, Italy

3 Faculty of Geosciences and Environment, Institute of Earth Surface Dynamics, University of Lausanne, Lausanne, Switzerland

4 Environmental Management Center, Mykolas Romeris University, Ateities g. 20, 08303 Vilnius, Lithuania its uncertainty, and its typology (e.g., hard/soft). The cited aspects have a strong influence on the spatial analysis methodologies that can be adopted (e.g., Kanevski and Maignan 2004; Daya et al. 2018). Moreover, the choice of a specific spatial data analysis methodology is also dependent on the objectives of the study and on users' specific knowledge. And, of course, there is no single approach that will always perform better than all the others. This means that finding satisfying solutions in specific applications requires a good understanding of the strengths and weaknesses of existing approaches. To that end, their behaviors need to be investigated in a wide variety of situations, which may ultimately lead to the creation of a sort of collection of "spatial data analysis recipes", capable to highlight their common "ingredients" and specific "taste".

These considerations prompted us to organize during the last three European Geosciences Union (EGU) General Assemblies (2016, 2017 and 2018) a conference session titled "Learning from spatial data: unveiling the geoenvironment through quantitative approaches" (conveners: S. Trevisani, I. Bogunović, M. Cavalli, S. Crema, J. Golay, P. Pereira, A. Piedade, G. Teza). This initiative has been promoted in the last few years also in the context of the annual meetings of the "Geosciences and Information Technologies" group (GIT, a section of the Italian Geological Society, http://www.gitonline.eu), with a scientific session specifically dedicated to spatial data analysis. The session has been envisioned for exploring how the modern earth scientists use advanced geospatial analysis methodologies in their research. The present topical session in the Journal of Environmental Earth Sciences has been promoted during the EGU-2017 meeting; the choice of the Journal has been specifically performed given the focus of the session on geoenvironmental challenges. In particular, the interest of the session and, ultimately, of the present topical collection, is on studies presenting intuitive and applied mathemati$\mathrm{cal} /$ numerical approaches, capable of highlighting their key 
potentialities and limitations for the interpretation, characterization and modelling of environmental processes.

Given the complexity and multidisciplinarity of the topic, the wide set of research issues addressed and the different theoretical approaches applied by the contributions of the special issue are not surprising. It is worth noting that even the more mathematically complex papers (e.g., Grillenzoni 2018; Gozzi et al. 2018; Fouedjio and Klump 2019) have a strong applicative counterpart. For example, Grillenzoni (2018) presents an open-source software implementing a very promising algorithm with interesting potential in the context of seismology. The compositional data analysis approach proposed by Gozzi et al. (2018) is extremely powerful in the context of geochemical analysis. Three other papers are related to the evaluation of soil resources, also with a focus on remote sensing technologies (Bogunovic et al. 2018; Polinova et al. 2018; Šestak et al. 2018). Related to remote sensing is also the work by Ahlmer et al. (2018), focused on natural hazards (floods). Another set of papers include works mainly related to geomorphometry, partly overlapping with remote sensing, covering various issues such as human impact on landscape (Xiang et al. 2018) and structure from motion photogrammetry applied in the context of debris-flow monitoring (Cucchiaro et al. 2018). Then, a paper covers the important topic of ground water quality and it is focused on background levels determination (Dalla Libera et al. 2018). Finally, the work of Trevisani and Boaga (2018) presents a data fusion approach applied to soft data for mapping the seismic impedance contrast in the historical city of Venice.

\section{References}

Ahlmer AK, Cavalli M, Hansson K, Koutsouris AJ, Crema S, Kalantari Z (2018) Soil moisture remote-sensing applications for identification of flood-prone areas along transport infrastructure. Environ Earth Sci 77(14):533

Bogunovic I, Pereira P, Coric R, Husnjak S, Brevik EC (2018) Spatial distribution of soil organic carbon and total nitrogen stocks in a karst polje located in Bosnia and Herzegovina. Environ Earth Sci 77(17):612

Cucchiaro S, Cavalli M, Vericat D, Crema S, Llena M, Beinat A, Marchi L, Cazorzi F (2018) Monitoring topographic changes through 4D-structure-from-motion photogrammetry: application to a debris-flow channel. Environ Earth Sci 77(18):632

Dalla Libera N, Fabbri P, Mason L, Piccinini L, Pola M (2018) A local natural background level concept to improve the natural background level: a case study on the drainage basin of the Venetian Lagoon in Northeastern Italy, Environ Earth Sci 77(13):487

Daya SBS, Cheng Q, Agterberg F (editors, 2018) Handbook of mathematical geosciences (fifty years of IAMG). Springer International Publishing, New York (ISBN: 978-3-319-78999-6)

Fouedjio F, Klump J (2019) Exploring prediction uncertainty of spatial data in geostatistical and machine learning approaches. Environ Earth Sci 78:38. https://doi.org/10.1007/s12665-018-8032-z

Giardino JR, Houser C (2015) Introduction to the critical zone. In: Giardino JR, Houser C (eds) Developments in earth surface processes, vol 19, pp 1-13. https://doi.org/10.1016/B978-0-44463369-9.00001-X

Gozzi C, Graziano RS, Frondini F, Buccianti A (2018) Innovative monitoring tools for the complex spatial dynamics of river chemistry: case study for the Alpine region. Environ Earth Sci 77(16):579

Grillenzoni C (2018) Sequential mean shift algorithms for space-time point data. Environ Earth Sci 77(9):336

Kanevski M, Maignan M (2004) Analysis and modelling of spatial environmental data. EPFL Press, Basel

Pereira P, Brevik E, Trevisani S (2018) Mapping the environment. Sci Total Environ 610-611:17-23

Polinova M, Jarmer T, Brook A (2018) Spectral data source effect on crop state estimation by vegetation indices. Environ Earth Sciences 77(22):752

Šestak I, Mesić M, Zgorelec Ž, Perčin A (2018) Diffuse reflectance spectroscopy for field scale assessment of winter wheat yield. Environ Earth Sci 77(13):506

Trevisani S, Boaga J (2018) Passive seismic prospecting in Venice historical center for impedance contrast mapping. Environ Earth Sci 77(21):733

Xiang J, Chen J, Sofia G, Tian Y, Tarolli P (2018) Open-pit mine geomorphic changes analysis using multi-temporal UAV survey. Environ Earth Sci 77(6):220

Publisher's Note Springer Nature remains neutral with regard to jurisdictional claims in published maps and institutional affiliations. 